\title{
Soberanía globalizada y la tesis de la reivindicación: una crítica a la posición de Macanchí
}

\author{
Globalized sovereignty and claim thesis: a critique of \\ Macanchí's position
}

RODRIGO LAERA*; WALTER KLEIN**

\begin{abstract}
Resumen: El objetivo de este trabajo es revisar la tesis de la reivindicación de la soberanía a partir de la posición crítica de Macanchí, argumentando que la idea de una soberanía globalizada abre problemas en torno a la injerencia económica del capital transnacional y profundiza el cercenamiento democrático.

Palabras Clave: soberanía; globalización; economía; democracia.
\end{abstract}

\begin{abstract}
The aim of this paper is to revise the sovereignty claim thesis from the Macanchí's critical position, arguing that the idea of a global sovereignty opens disputes around economic interference of transnational capital and deepens the democratic curtailment.
\end{abstract}

Keywords: sovereignty; globalization; economy; democracy.

\section{Primero: introducción}

Recientemente, Macanchí (2015) ha señalado que existe una especie de soberanía globalizada, sus dos tesis centrales son: (a) que la soberanía de cada nación ha encontrado nuevas oportunidades de desarrollo con la globalización; sin embargo, (b) debido a que la autoridad del estado se ve vulnerada por la presencia de lo trasnacional, se hizo posible el desarrollo de la tesis de la reivindicación, que sirvió para justificar el "caudillismo en Latinoamérica". Ambas tesis se encuentran enlazadas al presupuesto de que los estados deben adecuarse a los tiempos de globalización, dando lugar a una nueva forma de soberanía que se encuentre integrada a los poderes transnacionales. Estas ideas se enmarcan dentro de lo que son los distintos enfoques acerca de lo que se suele llamar post-soberanía, en la cual la autoridad de un estado sobre sus instituciones y su patrimonio se encuentra constantemente negociada con poderes externos (ej., MacCormick, 1996; Habermas, 2000; Keating, 2001).

Recibido: 07/08/2016. Aceptado: 02/01/2018.

* Investigador del Consejo Nacional de Investigaciones Científicas y Técnicas (CONICET, Argentina); autor del libro Los desvíos de la razón, Miño y Dávila, 2011, así como de numerosos artículos en diversas revistas académicas; rodrigolaera@gmail.com

** Universidad de Moreno, división de coordinación de proyectos en ciencias económicas; wklein_ar@yahoo.com 
El objetivo de este trabajo es discutir tanto $(a)$ como $(b)$, argumentando contra $(a)$ que aquello en lo que Macanchí ve como una "oportunidad de desarrollo" en realidad es, en el mejor de los casos, un proceso de injerencia económica y cercenamiento democrático; y contra $(b)$ que la tesis de la reivindicación es valiosa justamente por oponerse a ambos procesos. En el siguiente apartado se explorará la idea de soberanía globalizada en relación con el punto $(a)$, en el tercer apartado presentará la tesis de la reivindicación en relación con $(b)$, tomando como ejemplo el poder trasnacional del sistema financiero. Finalmente, se expondrá brevemente la idea de lo que sería una recuperación soberana mediante los activos del estado.

\section{Segundo: soberanía globalizada como super-estructura}

Partiendo de una concepción elemental, la noción de soberanía hace referencia a la independencia política de un estado para gestionar sus recursos, lo que implica una barrera legal para la injerencia extranjera en la jurisdicción de dicho estado. Bajo la doctrina de no intervención o no injerencia, la de soberanía es una noción tanto jurídica e institucional. En sentido estricto, se trata de una institución jurídica que se encuentra legitimada mediante un orden político que se fundamenta a partir de la organización de estados independientes, estados cuyos gobiernos son las principales autoridades en un determinado territorio (cfr., Hinsley $1986^{1}$ ).

Si bien Macanchí está en lo cierto al sostener que la globalización influye en la toma de decisiones sobernas, parece complicado aceptar que esto deba determinar las decisiones políticas e institucionales en general. En efecto, un estado soberano puede tomar una decisión influido por una circunstancia externa, pero esto no quiere decir que deba tomarla $a$ causa de una circunstancia externa. La influencia del poder global es evidente en cualquier toma de decisiones, pero esto no quiere decir que el estado deba ser gobernado por el poder global en desmedro de su soberanía ${ }^{2}$. Y es, justamente, esa toma de decisiones soberanas lo que defiende la tesis de la reivindicación. Macanchí incurre en una especie de falacia naturalista: que la globalización restrinja la soberanía de un estado, no implica que dicho estado deba adecuarse a ese hecho y no deba hacer nada al respecto. Que un estado no pueda ser completamente autárquico, no quiere decir que deba estar determinado por poderes trasnacionales o que la noción misma de soberanía deba ser revisada en vistas de la influencia de la globalización. Una soberanía global parece ser más bien una contradicción.

No obstante, quedaría por aclarar a qué se refiere Macanchí con globalización, si a la cultura en general, a la economía o, al menos, a ciertos aspectos de la macroeconomía. Se debe caracterizar de alguna manera, si no se quiere dar la impresión de que es simplemente una palabra de moda. Supóngase que se refiere a un sentido amplio de globalización: como el drástico aumento de las posibilidades de la interacción humana por sobre las divisiones geográficas y políticas existentes. Aun en este sentido, la globalización no implica que el estado deba dejar de tomar decisiones en vista del bien común y que deba abandonarse el

1 De hecho Hinsley señala que la noción de soberanía presupone la de una autoridad política.

2 Algo en lo que ha insistido U. Beck, incluso al definir el proceso de la globalización como aquel en que los estados nacionales soberanos se entremezclan e imbrican mediante actores transnacionales y sus respectivas probabilidades de poder, orientaciones, identidades y entramados varios. Véase: Beck (1997/2004). 
sentimiento de pertenencia nacional. Que los estados se encuentren influenciados por circunstancias externas no implica necesariamente que tengan que adecuarse a ellas. Macanchí se refiere a integración de los estados dentro de un marco supranacional -léase comunidad internacional- que se impone mediante la superestructura de la globalización y cuya naturaleza ofrece nuevos desafíos, tanto sociales como económicos. Así, Macanchí sostiene que "la soberanía está en crisis, porque muchas instituciones o estados no se acoplan a diversas realidades históricas que en la actualidad en el mundo se están produciendo", para luego agregar que "los estados más fuertes son aquellos que poseen una conducción política, esta debe estar orientada a las correctas y productivas ventajas que se pueden obtener de la globalización". Todo esto centrándose en las ventajas de insertarse en una economía globalizada. La fe de Macanchí en el fenómeno globalizador encaja dentro del marco de una economía neo-clásica: la globalización -y con ello el libre intercambio- produce una mejora sustancial de la productividad y del ingreso en los estados que participan de ella. ${ }^{3}$

Dejando de lado lo qué es una realidad histórica y como interpretarla (por supuesto, cómo oponerse al Espíritu de la Historia si toda oposición implica ser arrollado por ella), cabe mencionar que las correctas y productivas ventajas, sobre todo económicas, de la globalización son asimétricas. Es decir, Macanchí presupone que en todo intercambio entre estados, o entre un estado y un sector privado, se realizan de manera equilibrada. Esto a su vez presupone que un intercambio global conlleva un beneficio global. Sin embargo, este presupuesto está lejos de ser indiscutible, pues existen intercambios desiguales, sobre todo cuando se trata de intercambios entre estados de centro y de periferia. Los estados de centro son aquellos que por su estructura, su historia y su poder económico ejercen una influencia perceptible sobre el curso de los acontecimientos. En cambio, los estados que conforman la periferia son los que intentan adecuarse a dichos acontecimientos. Esto quiere decir que en todo intercambio quienes influyen sobre los acontecimientos tienen ventaja sobre quienes pretenden adaptarse a ellos. Si el intercambio fuera libre, quienes estuvieran en una posición privilegiada podrían influir en los acontecimientos en beneficio propio, incluso en detrimento de los estados periféricos. Por lo tanto, resulta cuestionable que el proceso globalizador ofrezca las mismas posibilidades de desarrollo a los estados que tienen un lugar en la periferia que aquellos que tienen un lugar en el centro ${ }^{4}$.

Llegados a este punto, resulta importante destacar que la soberanía no es una noción económica, aunque muchas veces pueda usarse la expresión "soberanía económica". Un término mejor sería "autonomía económica" (cfr., Jackson, 1999); lo que tampoco quiere decir que la soberanía y la economía no estén relacionadas. La soberanía de un estado depende, en parte, de la autonomía económica -y esto es lo que analizaremos en el último punto de este

3 De hecho esto se relaciona con la teoría de las ventajas comparativas de Ricardo, al suponer la existencia de una perfecta armonía de intereses entre Estados. Así, con la globalización se impone el libre comercio, el cual parece tener una tendencia innata a mejorar la situación de quienes mantienen relaciones comerciales, abaratando los productos y estimulando la producción de otros bienes. Para otros niveles de desigualdades producto de la globalización véase: Walby (2009).

4 En materia económica esto puede combinarse con la hipótesis Prebish-Singer acerca de las asimetrías en los mercados. Dicha hipótesis señala que, debido a la disparidad de los mercados de trabajo nacionales, los aumentos de productividad en los estados de centro tienden a trasladarse a los costes factoriales, mientras que en los estados de la periferia se traducen en reducción de los precios, dando como resultado una asimetría en la distribución de los beneficios del comercio. 
trabajo, donde la autonomía económica pasa por el usufructo de los activos del estado por parte del mismo estado. Por lo tanto, en lugar de pensar en una disminución o pérdida de la soberanía económica, sería más claro pensar en los desafíos que los estados enfrentan al perseguir políticas económicas nacionales, especialmente en la época del transnacionalismo y la globalización.

Al igual que antes, la de autonomía económica no es una noción que presuponga que la economía se encuentre aislada o sea completamente autárquica, sino que a pesar de estar influenciada por factores extrínsecos, no está controlada por estos $-\mathrm{o}$ al menos no debería estarlo desde un ideal democrático. La cuestión en este punto es de matices en torno a una disyunción elemental: participación o control; es decir, parece un dudoso presupuesto que la participación en la economía mundial implique un control por parte de esta en las decisiones soberanas de quienes participan ${ }^{5}$. Desde este punto de vista, cabe preguntarse si es necesario que los estados deban estar intervenidos por organizaciones que representan a la economía mundial para participar de dicha economía. Para expresarlo en términos de economía política: si las organizaciones controlan la matriz productiva de los estados nacionales o son los estados nacionales, en condición de soberanos, quienes determinan una matriz de desarrollo, que las organizaciones de la economía mundial deben respetar o ajustarse. Según Macanchí, los gobiernos latinoamericanos, en la última década, habilitaron una tesis acerca de la soberanía que es equivocada, porque la matriz de desarrollo vendría impuesta a causa de la globalización -léase la economía mundial. Así, según este autor, pareciera que los estados deben insertarse en la organización económica mundial y no viceversa.

Otro de los problemas en torno al concepto de soberanía es ¿hasta qué punto la falta de soberanía de un estado socaba su ideal democrático? Como señala Mikler (2011), gran parte del debate que domina la literatura de la globalización ahora gira en torno a la medida en que los actores estatales y no estatales comparten la autoridad y cómo lo hacen. Sin embargo, en lugar de decir que la regulación está impulsada por actores no estatales u otros estados, la tesis de la reivindicación sostiene que la autoridad para tomar decisiones políticas parte del sector público afectando al sector privado, y que el estado es responsable de las regulaciones del mercado, sobre todo cuando el mercado no es capaz de asignar recursos de manera eficiente $^{6}$. Ahora, si nos encontráramos arrastrados por una especie de superestructura a la que, a fin de cuentas, estuviéramos destinado a adecuarnos, entonces cabe preguntarse qué lugar podría ocupar la democracia. Esto recuerda a la imagen descripta por Giddens (1999) de una fuerza super-estructural -una especie de jaggernaut sistémico que domina cualquier acción política- que relega el ideal democrático a un nivel meramente abstracto. Sin embargo, más allá de la metáfora trazada por Giddens, la esfera pública del estado no es algo impersonal, sino que sus acciones son conducidas por individuos que tienen un efecto causal sobre su comunidad. Quizás la defensa de este ideal democrático sea una razón suficiente para reflotar

5 Incluso si entendemos como economía mundial a las diferentes organizaciones que producen e intercambian bienes entre sí, en un entramado territorial que trascienden la categoría de nación.

6 Piénsese, por ejemplo, en las externalidades negativas debido a los costos que puede sufrir un estado como resultado de una transacción económica entre otros dos estados. O por ejemplo casos en los que el costo social marginal es superior al beneficio cuando se trata de la producción o el consumo. 
la tesis de la reivindicación de la soberanía7. Nuevamente, la soberanía afecta directamente a la democracia, porque en un ideal democrático la toma de decisiones debe fundamentarse en procedimientos normativos de cada estado, defendidos racionalmente a partir de la igualdad entre los miembros y que tienen, en principio, el deber de obedecer. Esto no quiere decir que no pueda haber soberanía sin democracia, ni que tampoco que pueda haber democracia sin soberanía. No hay una identidad entre ambas, aunque se complementan. La democracia alude a una forma de legitimización política, mientras que la soberanía alude a la autodeterminación de tales políticas. En un estado idealmente democrático las decisiones de los representantes deben tomarse en vistas al beneficio de una mayoría, sin el perjuicio de una minoría. Dicho de manera rápida, serían decisiones Pareto-eficientes. Pero sin soberanía, estas decisiones, que surgen a partir de la igualdad entre los miembros, se verán distorsionadas por decisiones externas. Por lo tanto, según la tesis de la reivindicación de la soberanía, siendo una tesis normativa, debemos obedecer las leyes porque son el resultado de un procedimiento igualitario, donde el estado tendría la autoridad necesaria para sostener tales decisiones. Otro tipo de normatividad dará lugar a otra forma de entender la noción misma de estado ${ }^{8}$.

Lamentablemente, Macanchí nunca define el objeto que cuestiona, que es la tesis de una reivindicación soberana, lo cual no sería nada grave si al menos describiera alguna de sus propiedades, más allá de un mero repaso histórico del tema "soberanía". Quizás se pueda hacer algo al respecto. La tesis de la reivindicación de la soberanía posee al menos tres rasgos esenciales que están conectados entre sí. El primero consiste en un principio de separación de intereses. Este principio sostiene que los intereses del estado no deben estar sujetos a otros intereses institucionales, sino solamente al bien común. Y puede dividirse en dos: los intereses de un estado deben ser independientes de los intereses de las instituciones privadas, ya sean nacionales o multinacionales; y los intereses del estado deben ser independientes de los intereses de otros estados. Vale aclarar que con este principio no se está afirmando que un estado no debe guardar relación con las instituciones privadas o demás estados, sino simplemente que se garantiza la autonomía del estado en las tomas de decisiones de las políticas públicas. El principio de separación de intereses se conecta con un principio de neutralidad el cual sostiene que el estado no debe beneficiar a ningún sector privado por encima de otro, a no ser por una estrategia que tenga como fin al bien común. Este principio, que nos protege de la discriminación y el favoritismo, debe estar integrado a un criterio de razón política por la cual las decisiones se basen en una discusión libre de inclinaciones particulares.

Los debates idealmente democráticos no deberían ser epistémicamente mezquinos: más allá de que en un estado surjan visiones antagónicas del mundo, el debate político debería

7 Confróntese, por ejemplo, con Tansey (2011) quien sostiene que existe una relación clara entre la soberanía y la democracia, aunque el reconocimiento legal de la condición de estado (soberanía legal internacional) es de importancia marginal, y no debe ser visto como una condición necesaria para un régimen democrático. Sin embargo, esto aplica a comunidades donde las decisiones se toman democráticamente aun sin ser reconocidas como estados por la comunidad internacional.

8 Por supuesto, a un estado idealmente democrático se le podría añadir otras características, por ejemplo la de una distribución igualitaria y transparente de la información o la ausencia de sesgos cognitivos como el efecto halo (para esto último véase: Palmer \& Peterson, 2016). 
guiarse por la práctica de dar y recibir razones, por la generosidad de decidir como consecuencia de ellas, aunque quien debata no obtenga un beneficio propio. Por último, falta explicar el principio de identidad colectiva. Tal principio sostiene que un estado no es simplemente un aparato de gestión. Representa, dentro de un territorio, a una identidad que se constituye mediante la cultura, la ciencia, incluso la forma de vida de un determinado colectivo. Esta representación alcanza también al sentimiento de pertenencia y de continuidad de quienes son parte de la comunidad. Asimismo, el estado, como la entidad fundamental que representa la defensa de valores, tanto económicos, como sociales y culturales, es visto como un canalizador de arraigo y de cualidades específicas. Por lo tanto, sin una identidad colectiva capaz de movilizar recursos, no resulta particularmente propicio la defensa de valores que son considerados de importancia fundamental. Es decir, según el principio de identidad colectiva, la soberanía buscaría satisfacer las necesidades y propiciar el bienestar de quienes son representados por el estado. Asimismo, la injerencia de otros intereses merma la capacidad de obtener y ejecutar dichos recursos -y con ello la libertad- en detrimento de quienes están representados por dicha identidad.

Dejando de lado la discusión semántica y su consecuente análisis epistemológico (exceden las pretensiones de este trabajo), los tres rasgos de la tesis de la reivindicación de la soberanía no excluyen la idea de una interrelación entre estados o entre estados y otros actores externos, teniendo en cuenta la autoridad del estado para decidir sus políticas con el total derecho de excluir actores externos en su organización. Así, el proceso globalizador al que hace referencia Macanchí no resulta ser otra cosa que un proceso de injerencia económica y cercenamiento democrático para mermar estos tres rasgos.

En este sentido, sí cabe pensar a la globalización como una especie de super-estructura capaz de alinear todo tipo de intereses. En efecto, esta concepción conduce a su vez a la idea de una jerarquía entre el todo y la parte, donde uno debe adecuarse al otro. Para ejemplificar esto suele usarse el modelo de la Unión Europea (UE), donde la soberanía en términos de decisiones económicas implica una negociación con el parlamento europeo. Más allá de la interacción cultural y política entre países de la UE, la pertenencia no es igualitaria, existen países miembros que tienen más poder que otros -póngase el caso de Alemania. No obstante, esta no es la única manera de organizarse en beneficio mutuo, uno puede hacerlo respetando su soberanía. Así, es posible pensar otro tipo de asociación en la que haya cierta autonomía de los intereses soberanos, como por ejemplo es el caso de los BRICS, o tratados de comercio bilaterales que no requieren adecuar la política monetaria a una moneda única, ni sucumbir a las presiones no-proteccionistas.

En efecto, la experiencia de la moneda única europea está contenida dentro de un marco institucional distinto y ha requerido una adhesión por parte de los miembros. El marco institucional fue creado a través de sucesivos tratados, el primero firmado en Paris en 1851 y el último en Lisboa en 2009, dentro de un proceso que lleva más de cincuenta años. Este último tratado conformando un único estado con personería jurídica y un sistema político de democracia representativa. En ese contexto se intercambia el Euro teniendo al Banco Central Europeo como órgano regulador de la oferta monetaria, como el resto de los bancos privados que forman parte del sistema. El tamaño de las economías -en términos de PBI- de los países miembros coloca al bloque y a su moneda como una referencia mundial compitiendo con el dólar estadounidense. No obstante, las asimetrías económicas entre los 
países miembros termina ahogando las posibilidades soberanas de aumentar o disminuir la oferta monetaria, esa especie de estrangulamiento económico ha llevado a economías locales a generar sus propias monedas como fue el caso de la libra Bristol en el 2014 -Reino Unido mantuvo su propia moneda- o incluso plantear la independencia como lo está proponiendo Catalunya que, aunque tiene una larga historia a partir del siglo XVIII, se hizo más dramático con la crisis económica en estos últimos años. En cambio, los BRICS tienen una organización diferente con consecuencias diferentes, por lo menos eso es lo que parece. Este tipo de organización firma acuerdos bilaterales y trilaterales entre los países miembros, se presentan como bloque en el consejo de seguridad de la ONU, en el G20 y ante organismos internacionales de crédito, pero no hay una forma institucionalizada y ni miras de que esto ocurra -de hecho se respetan las características diferentes de cada forma de gobierno, es decir se mantiene la soberanía institucional y lo que ella representa en cada país miembro9.

El resultado de este tipo de intercambios, que respetan las particularidades soberanas de cada estado, se manifiesta en nuevas formas de integración y "cooperación” económica sin poner en riesgo los principios de la tesis de la reivindicación. Parece ser que esta nueva forma de vinculación económica y financiera hecha por tierra los anuncios de desaparición de los estados nación como se vislumbraba con la conformación final de la Unión Europea ${ }^{10}$. Los resultados económicos y sociales que se vienen produciendo en los países o en las zonas de baja productividad de la Unión Europea ponen en dudas si puede continuar con una forma la integración regional que no tenga en cuenta las decisiones sobernas, en materia macroeconómica, que responda a las necesidades propias de cada estado.

Como ya se ha sugerido, las asimetrías económicas favorecen a determinadas zonas en detrimento de otras, provocando inestabilidad política. Muchas veces a esta inestabilidad se le busca salidas locales a través de la creación de monedas o a través de la independencia, como fue el caso de Escocia en el 2014. La moneda única en países con un desarrollo disímiles se transforma en una suerte de dumping monetario interno, provoca tensiones hacia dentro de las zonas más desprotegidas, creando desempleo y tensión social. Esto podríamos trasladarlo al caso latinoamericano y los intentos de establecer una moneda única para darle un marco globalizador al libre comercio. No obstante, siguiendo a De Grauwe (2014) tiene que haber una correlación positiva entre los períodos de crisis y de crecimiento para que una moneda única tenga éxito, algo que en Latinoamérica no sucede.

9 Las reuniones de países se desarrollaron de esta manera: la primera reunión Rusia (2009), Brasil (2010), China (2011), India (2012), Sudáfrica (2013) y Brasil (2014) en esta ocasión estuvo presente Argentina. También es bueno mencionar la iniciativa vigente para la creación de un Banco de Desarrollo, sin que haya una moneda común, ya que están de acuerdo en no perder la soberanía monetaria - de hecho pretenden prescindir de dólar estadounidense como moneda de cuenta en el intercambio comercial y están completando sus reservas con oro, principalmente China y Rusia debido a que son productores. Además, la fuerza de sus economías en términos de extensión de su territorio, población y PBI los proyectan, según la tesis de Jim O Neill economista global de Goldman Sachs, al 2050 como las principales economías del mundo.

10 En este sentido un puede observar un proceso de financialización de las economías europeas en detrimento de otras formas de producción. En efecto, siguiendo a Hilferding (1923/1985), las finanzas son un depredador natural que ejercita su represiva función sobre la industria, el comercio y el trabajo. Si se globaliza dicho proceso, teniendo como resultado una desproporcionada expansión del intercambio de capitales, entonces ese ejercicio represivo también se globalizará sobre otras áreas de reproducción económica y social (Véase también, Fine, 2010). 
En el caso de la Unión Europea, se le suma las pocas herramientas de salida de su propia condición no avizorando, por parte de los estados dominantes, las respuestas a las demandas de los estados más vulnerables. En este sentido, la superestructura se percibe muy de lejos y, muchas veces, no se la reconoce como tal. Lo mismo se advierte en el acuerdo de asociación Transpacífico (TTP), ya que se producen las mismas asimetrías que se producen al interior de la Unión Europea. En ambos casos, la pérdida de soberanía conlleva la destrucción del empleo y coloca a los países en una situación de desprotección, pues su economía pasa a estar primarizada en una suerte de intercambio desigual del siglo XXI. En síntesis, parece interesante las nuevas formas de integración planteadas por los BRICS, donde se mantiene la moneda local, las medidas de protección de la industria sin recurrir a la $\mathrm{OMC}$, las reservas liquidas relacionadas con los términos de intercambio, etc. Esto no aplica dentro de los esquemas vigentes de TTP y la Unión Europea, que no estaría dando una mejor posibilidad a los países de no perder su soberanía.

\section{Tercero: Injerencia}

Macanchí conecta la tesis de la reivindicación de la soberanía con el llamado "populismo" latinoamericano, que introduce una suerte ambigüedad. Por un lado, la acción política realizada en beneficio del bien común que no conviene a determinados sectores se la considera populista. Pero, por otro lado, la acción política contraria, que no beneficia al bien común y que conviene a otros sectores, no es llamada anti-populista, sino que puede describirse como anti-democrática. En otras palabras, cuando no se está de acuerdo con un tipo de acciones cuyo objetivo es el bien común de las clases populares, pero con la que no se está de acuerdo, se la encasilla dentro de una política populista, mientras que un tipo de acciones con las que sí se está de acuerdo, se la encasilla como democrática. Así, ¿cómo resolver la diferencia entre acciones democráticas y populistas sin ser arbitrarios en dichas calificaciones? No hay respuesta a esta cuestión.

Ahora bien, Macanchí también presupone que la reivindicación de la soberanía es una tesis a favor de la centralización del poder político que no está a la altura del período histórico que nos toca. Sin embargo, esta es una visión monódica de la idea de soberanía, pues una de sus características es la policentralidad. Brevemente, la policentricidad de la soberanía consiste en que existen múltiples centros de decisión política dentro de un estado. Dicho de otra manera, puesto que hay distintas fuentes de autoridad dentro de una democracia representativa, la soberanía nunca llega a ser, en este sentido, absoluta (Morris, 2002). Sin embargo, la tesis de la reivindicación no es acerca de la policentralidad, ni implica que quede plasmada en una especie de una tiranía de estado. Por el contrario, resulta más intuitivo pensar no solo que la vulneración de la soberanía mediante fuerzas trasnacionales no conduce a una tiranía de estado -o "caudillismo"-, sino a un abandono de la autoridad del estado para decidir sus propias políticas. Es más, pensar en términos de soberanía nacional centrándose en la organización de la autoridad pública dentro del estado, no conduce a pensar temas relacionados con la soberanía de Westfalia, que se centra en la exclusión de actores externos de las estructuras de autoridad, sumado a la capacidad jurídica para actuar en el propio territorio. Confundir ambos tópicos conduce al supuesto que las tesis acerca de la organización y las propiedades del estado derivan de las tesis acerca de la exclusión de actores externos. La idea de reivindicación de la soberanía tiene como eje el reconocimiento mutuo de derechos entre estados. 
En los estados soberanos las normas se establecen por imperio de la ley, que dependiendo del tipo de organización política tendrá mecanismos más o menos intrincados, ahora la pregunta que haría falta responder es la siguiente: ¿cómo en el nivel mundial se puede establecer leyes democráticamente, sin que los intereses de un estado prevalezca sobre los otros? Dicho con otra pregunta, ¿cómo la soberanía de un estado puede convivir con la soberanía de otros estados?

\section{Cuarto: un forma de recuperación de soberanía a través de la autonomía económica}

En la historia reciente se desarrolla un hecho importante que marca el establecimiento de una pauta mundial a nivel organización del comercio y las finanzas: la utilización de dólar estadounidense como moneda de intercambio comercial a nivel mundial. Esto sucede con el acuerdo de Bretton Woods, en 1945, luego de haber ganado la segunda guerra mundial. Los países acordaron que Estados Unidos fuera el garante financiero del esquema monetario mundial, en ese acuerdo se establece que el dólar sea la moneda de referencia de las otras monedas y que, como garantía del dólar, los países se comprometen a entregar todas sus reservas de oro. Las reservas de oro mundial fueron a la base militar de Fort Nox, conformándose el "patrón oro"; una convertibilidad del dólar con el oro. Así, Estados Unidos acumuló las reservas de oro de todos los países miembros. La globalización de la moneda mundial para organización del comercio y las finanzas aumentó la hegemonía económica y financiera de Estados Unidos, a su vez, se crean el FMI (Fondo Monetario Internacional) y el BM (Banco Mundial) para monitorear y asistir a los países con desequilibrios en la balanza de pagos. De este modo, la moneda dólar estadounidense sobrepasa las fronteras de su propio país, mientras que las monedas locales quedan confinadas a sus respectivos territorios. La banca norteamericana se internacionaliza para actuar de intermediarios en las transacciones comerciales apropiándose de la conversión de monedas locales y el dólar estadounidense. La ruptura de este modelo se produce durante la guerra de Vietnam, en 1971, presumiblemente como consecuencia de la pérdida de confianza en el esquema monetario. Francia e Inglaterra reclaman la parte de sus reservas de oro y el presidente Nixon declara la inconvertibilidad de su moneda con el oro, y el acuerdo se rompe. Si bien se cae en una crisis mundial, el objetivo ya estaba cumplido: el dólar estadounidense se instala como moneda de reserva mundial.

Este breve relato, con la consecuencia de un nuevo orden económico mundial, demuestra cómo los estados pueden perder soberanía mediante la merma de autonomía monetaria. Es más la globalización financiera ha pasado ser un poder en sí mismo, de tal manera que su hegemonía sobrepasa las fronteras de los estados para instalarse de facto en las relaciones comerciales, incluso internamente. La moneda de referencia pasa a ser una moneda de la cual los países no tienen la posibilidad de crear, como sí la tienen de la moneda local. De modo que habiendo una moneda globalizada, utilizada como reserva de valor a prueba de las decisiones soberanas de los propios países, se produce un quiebre en la política monetaria de los países en desarrollo, donde la volatilidad del dólar puede ser obstáculo para equilibrar la balanza de pagos ${ }^{11}$. Un claro ejemplo de lo dicho puede verse en el acuerdo de asociación

11 Sobre todo cuando el dólar estadounidense cumple el rol de proporcionar liquidez en momentos de incertidumbre. 
Transpacífico, con el que se pretende crear una zona comercial y financiera que garantice la prevalencia del dólar estadounidense, prevalencia que es puesta en jaque a causa de la perdida de hegemonía con la creación de otros bloques como la Unión Europea o los BRICS (Brasil, Rusia, India, China y Sudáfrica).

En casos como este no se pone en juego la eficiencia en los mercados, bajo una ricardiana concepción de ventajas comparativas, al contrario se pone de manifiesto una jerarquía económica y política en detrimento de la soberanía de los estados menos favorecidos. En este intercambio desigual la transferencia de renta, vía precios de intercambio, van desde el país menos desarrollado al con mayor desarrollo relativo. De modo que los costes de oportunidad en la producción y el consumo con el comercio de cada país no coinciden con la relación de intercambio, a raíz de una posible carencia de policentralidad en materia de decisiones. En un orden policéntrico existen muchos centros de decisión, cada uno con un grado de autonomía que no está subsumido a una jerarquía bajo otra autoridad. Si la policentralidad es una propiedad de la soberanía, entonces la merma de autonomía económica como es una merma en la policentralidad tanto, también es de la soberanía.

Por un lado, una manera de garantizar autonomía monetaria es mediante ampliación de los activos del estado, pues estos no solamente amplían los fondos del estado, sino que contribuyen a la policentralidad de la toma de decisiones. Cuantos más activos tenga un estado, más capacidad de decisiones tomará en relación a la autonomía monetaria. El eje de la policentralidad se amplia y, con ello, sus potencialidades. Por otro lado, el desarrollo económico es un proceso que depende en gran medida de la acumulación de capital -en un sentido amplio- de cada estado. Esta acumulación reporta los beneficios macroeconómicos necesarios para sostener un orden social, y con ello la integración de los distintos actores para que el riesgo propio de especulación pase a ser riesgo de inversión o de producción.

Volviendo a la tesis de la reivindicación de la soberanía, cabe destacar también que la autonomía económica debe tener como objetivo fundamental -especialmente en el caso de Latinoamérica- hacer frente de manera progresiva lo que se conoce como "pobreza paradojal", donde las altas cifras de pobreza no se corresponden con la privilegiada dotación de recursos naturales, ni con los niveles de su producto bruto per cápita (Kliksberg, 2008). Lo que parece estar en el fondo de las posiciones como la expuesta por Macanchí, es considerar que la relación costo-oportunidad debe examinarse a partir de un beneficio económico respaldado en la tasa de crecimiento. Sin embargo, parece importante recordar el objetivo o finalidad del estado no es maximizar beneficios. Se objetará que si la tasa de crecimiento alcanza los niveles necesarios, entonces "derramará" sobre el conjunto de la comunidad y del estado, cayendo en un círculo virtuoso apoyado en un punto de equilibrio. Desde esta interpretación, la tesis de la reivindicación bloquea este círculo y el consecuente derrame, pues pone las trabas suficientes para impedir que procesos globales impacten, no solo en la economía, sino en la vida diaria. Esta objeción, basada en la "teoría del derrame" no tiene en cuenta que el crecimiento económico puede no ir acompañado por el desarrollo en cuestiones de bienestar social, pues la tasa de crecimiento no impacta directamente sobre la redistribución ${ }^{12}$. Explicaciones a partir de un fenómeno como el "desarrollo distorsionado"

12 Según datos de la Cepal, la pobreza en Latinoamérica en 1980 era del $40.5 \%$, en 1990 (auge de la liberación de los mercados y de los procesos globalizadores) subió al 48.4\%. En 2010 (auge de la tesis de la reivindicación) 
han sido claves para entender la desigualdad de políticas neo-liberales; políticas económicas que han permitido que los mercados globales dejen una dura huella en estados desprotegidos. La tesis de la reivindicación, en consecuencia, reclamaría una protección soberana ante los peligros de la globalización.

\section{Quinto: conclusión}

Si la soberanía es un poder emergente ${ }^{13}$, entonces sus límites que se pueden ampliar o reducir. La tesis de la reivindicación aspira a ampliar los límites soberanos del estado mediante la autonomía económica y sus instituciones. Esto es posible porque se ha tomado consciencia que someter los recursos y los activos del estado al escrutinio del mercado globalizado, como sugiere Macanchí, implica no tener en cuenta variables perjudiciales para el desarrollo del propio estado. Por supuesto, que la globalización brinda oportunidades de desarrollo, pero no por sí misma, sino por como los beneficios pueden ser redistribuidos mediante una política económica inteligente. Así, la tesis de reivindicación no es opuesta a la globalización, sino que busca convivir con ella teniendo en cuenta que la supervisión y la regulación no son un mero coste de transacción, sino que son también parte del desarrollo económico, es decir de la capacidad que tienen los estados para organizar sus actividades productivas. En consecuencia, la tesis de la reivindicación no sostiene que para ser soberano un estado deba aislarse de los poderes transnacionales, no es un tesis de blanco o negro acerca del aislamiento o la integración, es una tesis acerca de que la integración debe realizarse racionalmente y no a cualquier costo. Con la tesis de la reivindicación, finalmente, se trata de mantener la autonomía económica frente a un proceso de injerencia transnacional y de mantener la capacidad de decidir políticas frente al cercenamiento democrático propio de la idea de una soberanía globalizada.

\section{Referencias}

Beck, U. (2004). ¿Qué es la globalización? Falacias del globalismo, respuestas a la globalización. Barcelona: Paidós.

Buchanan, J. M. (1987). The constitution of economic policy. The American economic review, 77(3), 243-250.

De Grauwe, P. (2014). Economics of Monetary Union. Oxford: Oxford University Press.

Fine, B. (2010). Locating financialisation. Historical materialism, 18(2), 97-116.

Giddens, A. (1999). Consecuencias de la modernidad. Madrid: Alianza.

Habermas, J. (2000). La constelación posnacional: ensayos políticos. Barcelona: Paidós.

Hilferding, R. (1985). El capital financiero. Madrid: Tecnos.

Hinsley, F. H. (1986). Sovereignty. Cambridge: Cambridge University Press.

la pobreza bajó al $31.4 \%$, esto equivale a 23 millones menos de pobres. En términos de PBI, según fuentes del Fondo Monetario Internacional, Latinoamérica paso en 1980 de 1.5 mil millones de dólares a 2.7 millones de dólares en 1990, con un aumento de la pobreza en más de 8 puntos.

13 Para ampliar la idea de que la soberanía es un proceso emergente, véase Buchanan (1987) o más recientemente Salter (2015). 
Jackson, R. (1999). Sovereignty in world politics: a glance at the conceptual and historical landscape. Political Studies, 47(3), 431-456.

Keating, M. (2001). Plurinational democracy: stateless nations in a post-sovereignty era. Oxford: Oxford University Press.

Kliksberg, B. (2008). Más etica, más desarrollo. Buenos Aires: Temas.

Macanchí, M. A. (2015). Soberanía Globalizada. El caso latinoamericano. Daimon(66), 41-54.

MacCormick, N. (1996). Liberalism, Nationalism and the Post-sovereign State. Political Studies(3), 553-567.

Mikler, J. (2011). Sharing sovereignty for policy outcomes. Policy and Society, 30(3), 151160.

Morris, C. (2002). An essay on the modern state. Cambridge: Cambridge University Press.

Palmer, C., \& Peterson, R. (2016). Halo effects and the attractiveness premium in perceptions of political expertise. American Politics Research, 44(2), 353-382.

Salter, A. (2015). Sovereignty as exchange of political property rights. Public Choice, 165(2), 79-96.

Tansey, O. (2011). Does democracy need sovereignty? Review of International Studies, $37(4), 1515-1536$.

Walby, S. (2009). Globalization and Inequalities: Complexity and Contested Modernities. London: Sage. 